experience. The wisdom of men such as Ramsay, Arrhenius, W. H. Perkin, William Bragg and Karl Pearson did not derive from knowledge deliberately learned or consciously memorized. The man of science must also resist the very human temptation to take a narrow view of his work and to use it as an instrument for the furtherance of his own worldly reputation. Likewise, he will not allow partisanship for one study to prejudice him against excellence in other fields, of science or the humanities. For both the man of science and the scholar complete intellectual honesty is essential, and the same code covers both. For the scientific worker, the chief danger to be guarded against is the materialistic view that science is to be judged according to the practical inventions that follow in its wake. This is a narrow view and loses sight of ultimates. The virtue of a fine scientific research is similar to that of a fine poem, and each can have a profound effect on human thought, and on the understanding of the universe in which we are set.

On the second evening of the meeting, the Bishop of Birmingham addressed a crowded session of the Science and Religion Group. Defining religion as experience of ultimate reality, Dr. Barnes stated his belief that the minds of mankind make the world as it is known to us; these human minds must be akin to that of God, or science would be impossible. The advice "seek and ye shall find" is as appropriate to the laboratory as to the Church. The pure Christian faith rests on mysticism, strengthened by morality and joined to scientific knowledge; its formulation is not fixed but will change as the generations pass. The failure of traditional forms of religion imposes on all teachers the duty of forging their own religious understanding and passing this on to their pupils.

The third evening was devoted to the Science and Citizenship Lecture, delivered to a public audience by Prof. W. T. Astbury, in the Memorial Hall, Sheffield. Prof. Astbury emphasized the need for a greater appreciation of the work of pure scientists by leaders of industry. Such examples as the production of textile fibres from globular proteins and the release of atomic energy show that pure research finds application in the most unexpected directions. Recent developments in the textile industry show also that the craftsman and the scientific worker can learn much from each other, once the difficulties of mutual understanding are resolved. It is here that the educationist can play his part by ensuring that all members of the public have some appreciation of the spirit and methods of science, and the potentialities for good or evil of its applications. The human race, owing to its discoveries having outrun its moral standards, is in grave danger of descent into the abyss of ruin and destruction. The avoidance of this catastrophe, and the development of the constructive spirit in world affairs, depends in no small degree on the efforts of science teachers.

During the meeting, members heard a number of stimulating and informative lectures by members of the staff of the University of Sheffield. Prof. W. Sucksmith, on "Magnets and Magnetism", gave a lucid exposition of the modern picture of magnetism, with especial reference to the domain concept, and a review of recently developed magnetic materials; Prof. J. H. Andrew, on "Metallurgy as a Profession", outlined many examples of the applications of metallurgy, with a useful discussion of careers open to those with qualifications in this subject; Prof. Harry Moore, on "The Physics and Chemistry of
Glass", dealt with the history of glass manufacture, giving many useful data regarding modern glasses, and the results of research into their structures; Prof. L. E. S. Eastham, on "The Evolution of a Developmental Process", illustrated the phenomena of insect metamorphosis on the assumption that the rates of developmental processes are controlled by genes; Dr. T. B. Smith, on "The New versus the Old in the Theory and Practice of Analysis", considered the impact of new ideas of physical chemistry on the teaching of analytical chemistry in 'sixth forms', both from the theoretical and practical aspects ; and Dr. V. M. Conway, on "Pollen Analysis", outlined the development of this study and the many uses to which it can be put.

Science masters found much of interest in the excellent experimental demonstrations arranged by the Departments of Botany, Chemistry, Glass Technology, Metallurgy, Physies and Zoology of the University of Sheffield, and the members' exhibition showed its usual high standard of ingenuity. The publishers' and manufacturers' exhibitions were also popular, and the comprehensive visits' programme enabled members of the Association to see many typical local industries.

\section{METEOROLOGY AND THE PROPAGATION OF RADIO WAVES}

THE development of radio communication and radar during the War emphasized the fact that the propagation of metre and centimetre waves was greatly influenced by the meteorological conditions in the lower atmosphere. The subject was of such importance that a large-scale investigation of the phenomena involved was organised in Great Britain as a co-operative effort between the staffs of several radio research establishments and of various sections of the Services. The Navy, Army and Air Force, the Ministries of Supply and Aircraft Production, the Meteorological Office and the National Physical Laboratory, and also the Research Laboratories of the General Electric Co., Ltd., each played an important part in this work. The experiments were conducted over both land and sea paths, along which both the radio transmission characteristies and the meteorological conditions were measured simultaneously. The installations at one end of each path comprised a radio-sending station emitting a known amount of radiation towards the receiving station at the other end of the path, where the field strength of the arriving waves was measured and continuously recorded. In the case of one of the oversea paths the meteorological conditions, temperature, pressure and humidity, were measured at various heights along the path by flights of aireraft between the sending and receiving stations. These observations were supplemented by other measurements made from a captive balloon attached to a ship located along the path. In the case of other paths, the meteorological conditions were largely deduced from the normal daily weather charts, supplemented by observations at the terminal points.

This 'field' type of investigation was supplemented by many subsidiary experiments on the properties of the constituents of the atmosphere and the effect which these might have on the propagation of very short radio waves through it. Much theoretical work was also carried out by individual workers on 
both the meteorological and radio aspects of the whole investigation.

As the various items of all this work reached appropriate stages, reports were prepared and issued as confidential or secret documents under the restric. tions of war-time conditions. But the value of the research from the point of view of the scientific world has now been considerably enhanced by the fact that many of the results obtained have been placed on permanent record in the form of published papers. In the first place, the propagation of ultrashort waves formed the subject of one of the sessions of the Radiolocation Convention of the Institution of Electrical Engineers held in March 1946. The resulting papers and lecturettes were published in a special number of the Institution's Journal (93, Part IIIA, No. 1, 1946). This Convention was followed in April of the same year by a Joint Conference held by the Physical and the Royal Meteorological Societies, at which the various aspects of the influence of atmospheric conditions on the propagation of radio waves was discussed in considerable detail ; and in Nature of June 29, 1946 (157, 860), Prof. P. A. Sheppard gave a detailed account of this Conference and of the various papers presented at it.

The report of the latter Conference has now been published by the Physical Society as a special volume entitled "Meteorological Factors in Radio-Wave Propagation" (price to non-members 24s. including postage). This volume contains the full text of the ten papers read at the meeting, together with eleven other papers describing work on various closely related subjects. Dr. J. A. Saxton gives an account of the experimental determination of the dielectric properties of steam for frequencies between 3,000 and 20,000 Mc./s. (wave-lengths 1.5-10 cm.). The results of such measurements were used to estimate the amount of attenuation to be expected, due to atmospheric water vapour, in the transmission of these waves through the lower atmosphere. The estimated values of such absorption are found to be reasonably consistent with those obtained from theoretical considerations. In four subsequent papers the same author, in one case jointly with J. A. Lane, has studied experimentally and theoretically the anomalous dispersion of water in the centi. metre wave-range. The results of this work have provided a detailed knowledge of the refractive index and absorption coefficient of liquid water over a wave-length range from $10 \mathrm{~cm}$. down to a few millimetres, and of the variations of these quantities over the temperature range $0^{\circ}-40^{\circ} \mathrm{C}$.

In a paper entitled "Observations of Unorthodox Radar Vision in the Vicinity of New Zealand and Norfolk Island", Dr. F. E. S. Alexander presents and analyses many observations of anomalous wave propagation obtained by the operators of radar stations on wave-lengths of 10.5 and $150 \mathrm{~cm}$. Another paper, by J. A. Ramsay, describes the results of further observations made at radar stations using wave-lengths of $1 \cdot 25,3$ and $10 \mathrm{~cm}$. The conditions of propagation were studied at a nominally fixed range, by raising the reflecting target to known heights above the sea by means of a balloon. The results confirmed the prediction, made on theoretical grounds, that anomalous propagation would be experienced on a wave-length of $1.25 \mathrm{~cm}$. to a much greater extent than on $10 \mathrm{~cm}$.

The remaining papers deal with various aspects of the vertical gradient of refractive index in the atmosphere and its effect on the propagation of the very short radio waves under consideration. Dr. G. G. Macfarlane describes a method of deducing the refractive index gradient in a stratified atmosphere from radio observations: while G. A. Bull has provided a note on errors in the measurement of the refractive index consequent upon errors in the meteorological measurements from which the index is deduced. Using information provided by published weather charts, supplemented by some special measurements made in Great Britain, Dr. A. C. Stickland has studied the average condition of the atmosphere as a refracting medium for the propagation of radio waves. From this empirical study, it is shown that the average refractive index of the lower atmosphere varies logarithmically with height, the actual radius of curvature of the path of the waves increasing linearly with height above the earth's surface.

In a field of investigation such as this, where the meteorologist and radio scientist meet on common ground, it is clearly desirable that there shall be some agreement on the definition of what may be termed a 'standard atmosphere', to which both theoretical and experimental investigations may be referred. It is therefore very appropriate that the publication now under review should include a paper by A. C. Best entitled "A Standard Radio Atmosphere for Microwave Propagation". The author discusses three possible definitions of standard atmosphere, one of which is already in use for aeronautical purposes; but he suggests that the final choice of definition for the standard radio atmosphere must be made by the radio investigator rather than by the meteorologist.

All the work described above represents the conclusion of a very satisfactory and highly successful series of investigations initiated and conducted under war-time conditions. It demonstrates the ability of a large body of scientific workers and Service personnel to plan and conduct in an efficient manner a very complicated research programme in the laboratory and in the field. In spite of the varying interests of the many individuals concerned, they worked together as an enthusiastic team and were inspired in the main by two British Government committees. One of these was under the chairmanship of Sir Edward Appleton, who at the end of his introductory paper to the joint Conference mentioned above acknowledges with pleasure the collaboration he received from its members. $\mathrm{He}$ also states that his committee, or, to give it the full title, the Ultra-Short Wave Panel of the Ministry of Supply, had the good fortune to work in close collaboration with the U.K. Joint Radio Meteorological Committee, under the chairmanship of Sir Nelson Johnson, and also with the U.S. Wave Propagation Committee under the chairmanship of Dr. C. R. Burrows.

R. L. SMITH-ROSE

\section{RELEASE OF INFORMATION ON ATOMIC ENERGY}

$T$

WO lists of British reports on atomic energy, which had been 'declassified' and made available for purchase through H.M. Stationery Office, P.O. Box 569, Cornwall House, London, S.E.1, were announced last year (Nature, March 22, p. 411, September 27, p. 445). The following further twentythree reports have now been released and should, wherever possible, be ordered by B.D.D.A. number ; if this is given, no other identification is needed. 